\title{
OSPREYS NEST SUCCESSFULLY DESPITE CONFLICT WITH BALD EAGLES
}

JEAN BANCROFT, 306-200 Tuxedo Blvd., Winnipeg, MB R3P OR3

For the past several years, Ospreys have used a nest built by them on a Manitoba Hydro substation structure at Grand Marais, Manitoba (Fig.1), thus attracting the attention of numerous birders and the general public. ${ }^{1}$ In April 1997, a pair of Bald Eagles arrived before the Ospreys and appeared to take over the Osprey nest. Informants told me that for several days, beginning April 26, a battle ensued between the Bald Eagles and the Ospreys, the latter diving down on the eagles. Note that Bald Eagles have even been known to attack Osprey nestlings. ${ }^{7}$

Ultimately, the Bald Eagles did not use the Osprey nest (first built in 1988 and added to every year), but up to the third week in May the eagles were reported attacking the female Osprey while she

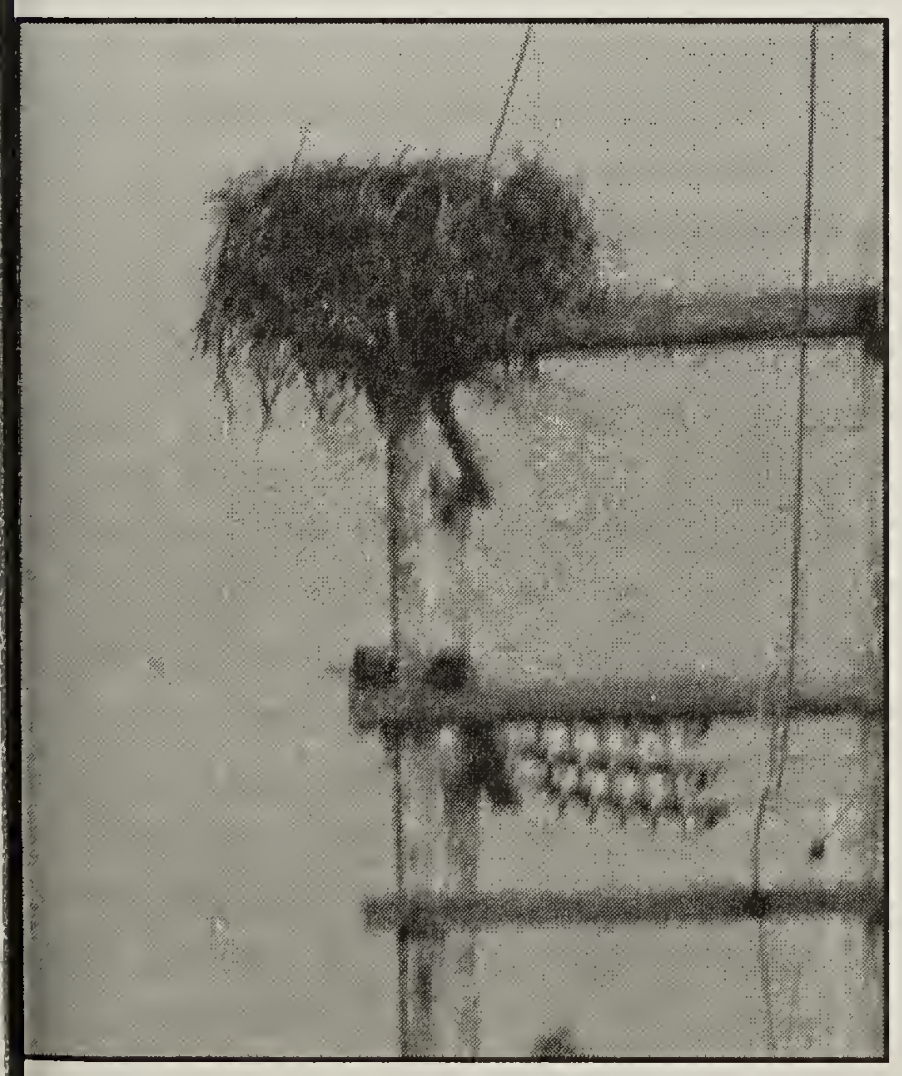

Figure 1. Old Nest

Ernie Taylor was sitting in a new nest built about 200 $\mathrm{ft}$. away. Initially, under pressure from the eagles, the Ospreys began building a second nest atop a nearby energized hydro pole, whereupon the Department of Natural Resources collaborated with Manitoba Hydro and immediately erected a new pole with a nest platform for the birds. It has been noted that "the Osprey habit of carrying long wet sticks to the top of hydro structures has caused lines to trip out and even set fire to the tops of the structure.... The potential for injury to birds themselves is very high." According to Rod Cotton, Natural Resources, the new wooden pole is 35 $\mathrm{ft}$. in height, with a wooden platform $4 \mathrm{x}$ $4 \mathrm{ft}$. on top ( Fig.2). About $20 \mathrm{ft}$. away, a heavy wooden beam was attached at right angles and about $10 \mathrm{ft}$. from the top of a live hydro pole to serve as a

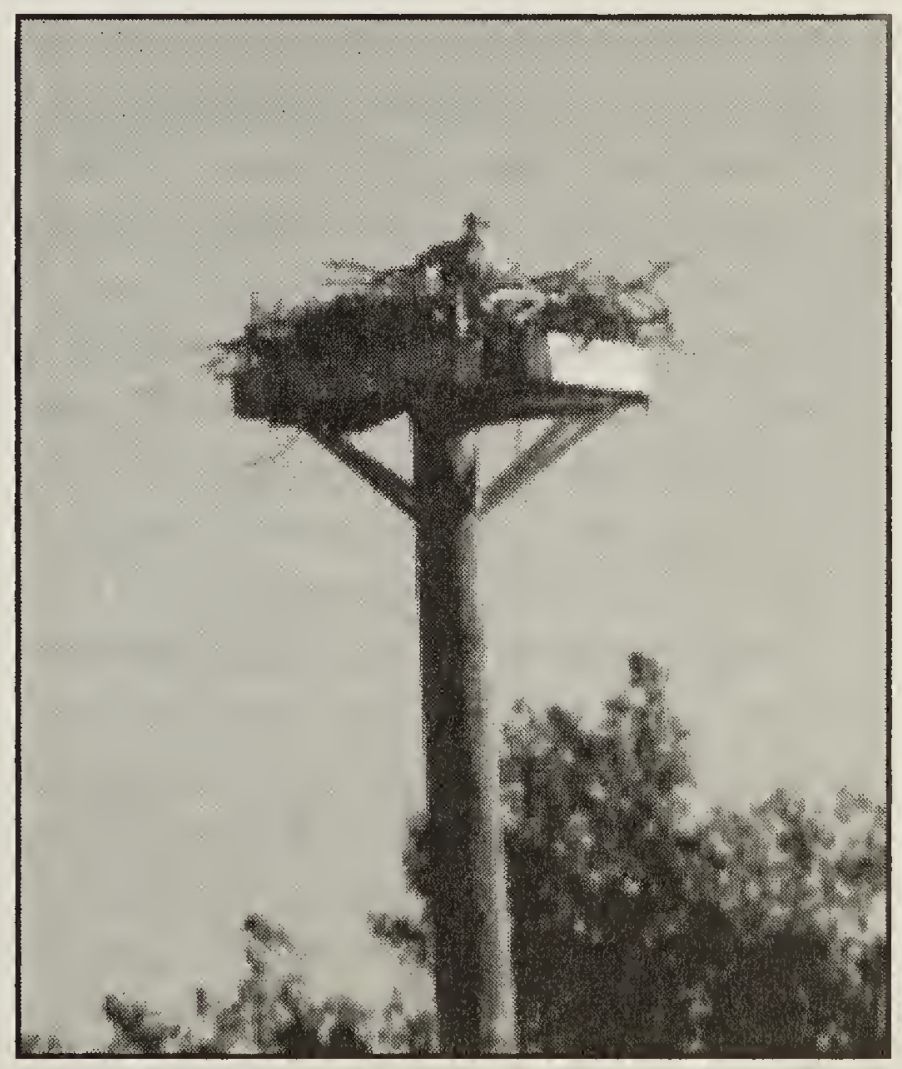

Figure 2. New Nest

Ernie Taylor 


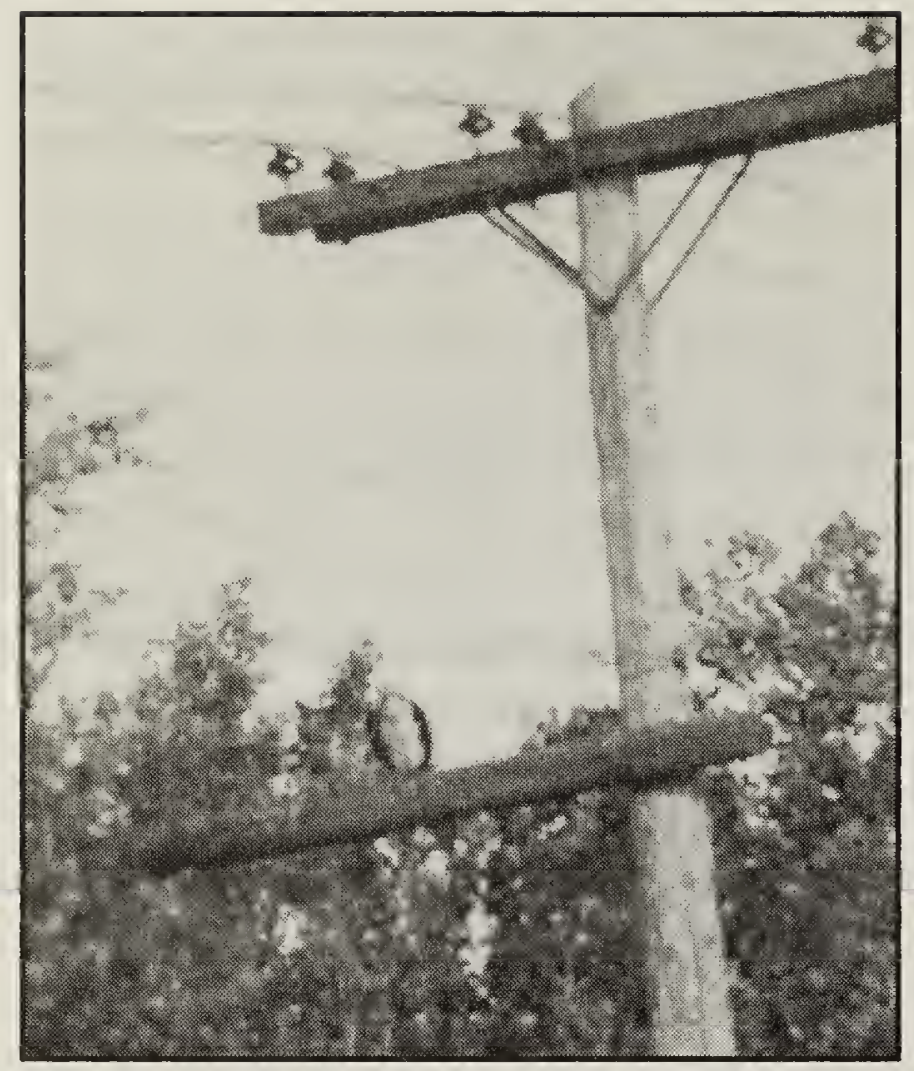

Figure 3. Perching post across from new nest.

Ernie Taylor

perching post ( Fig.3). Other structures installed specifically to benefit nesting Ospreys have been described by various authors. ${ }^{3,5,8,9}$

On June 1 and 2, I found the female Osprey sitting on the new nest which was comprised of large, heavy sticks built on top of the new pole platform. The new nest was rather shallow in comparison with the old nest. The female appeared restless and I wondered if she was turning the eggs. Godfrey states that incubation takes 3233 days (up to 38 days in Europe). ${ }^{4}$ On June 9 , it was reported that the female was still sitting. It may be noted that while both male and female Osprey share in incubation, it appears that only the female sits at night. ${ }^{2}$ On June 28 and July 1 , one young was observed being fed. Gerald Jones, who had spent several hours on July 7 observing the nest, reported that the male came with a fish and sat on the edge of the nest, then gave the fish to the female. She partook and fed the young, then the male picked up the remains and flew

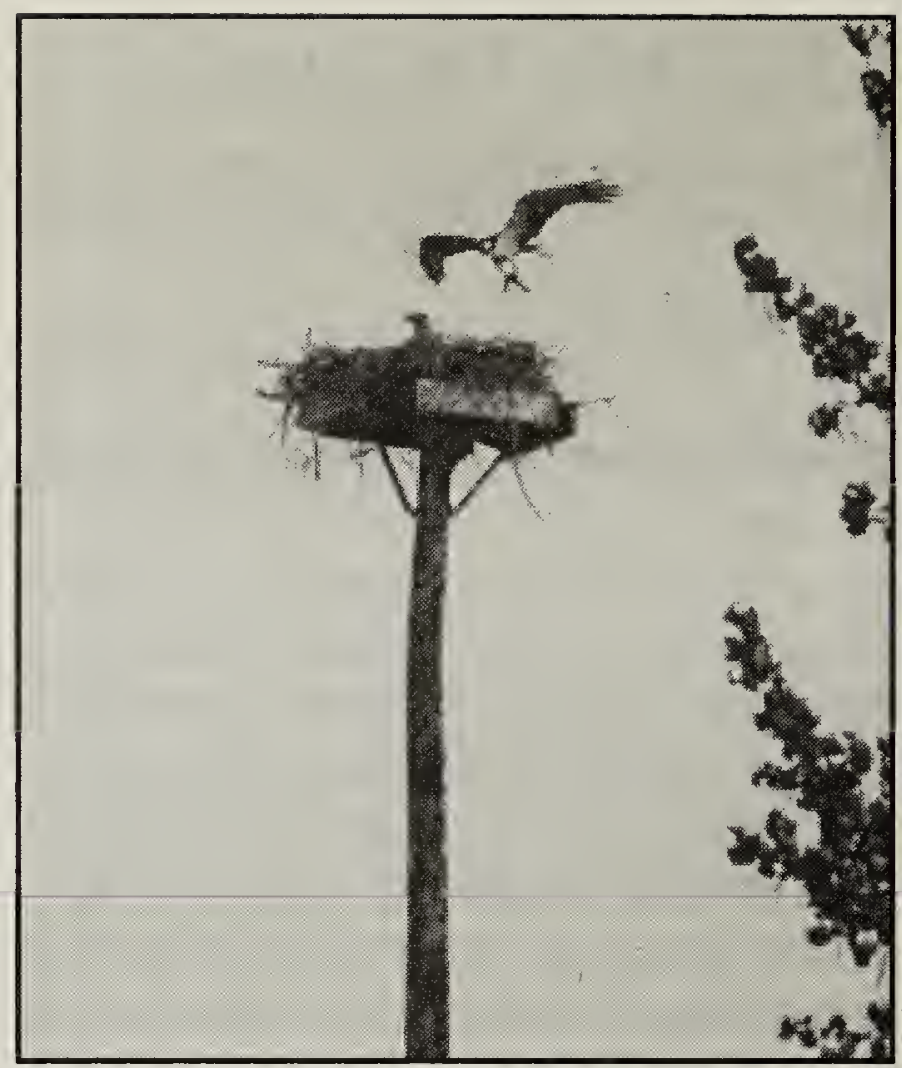

Figure 4.

Ernie Taylor

away. He sat on the nearby perching post for a long time, apparently guarding the nest. Three young were in the nest on July 20.

The Ospreys were now, apparently because of the growing nestlings, making the nest larger. I saw the three fair-sized young at $1830 \mathrm{hr}$. August 7. The female was perched on the rim of the nest and "kee-kee-kee" calls could be heard coming from the young, but the male continued to perch across the road on the perching post. At $1050 \mathrm{hr}$., August 10 , the male came with a fish and the female fed the young ones ( Fig.4). At 1900 hr., I watched for 20 minutes, but no male came; the female was perched on the edge of the nest. One large wing of a young bird could be seen flapping several times. I was informed that on August 25 three young were still being fed at the nest. Gerald Jones was present on August 31 when all three fledglings ( Fig.5) left the nest and flew about a mile down the road. Jones said it was a thrilling and exciting sight! This family of Ospreys was last 


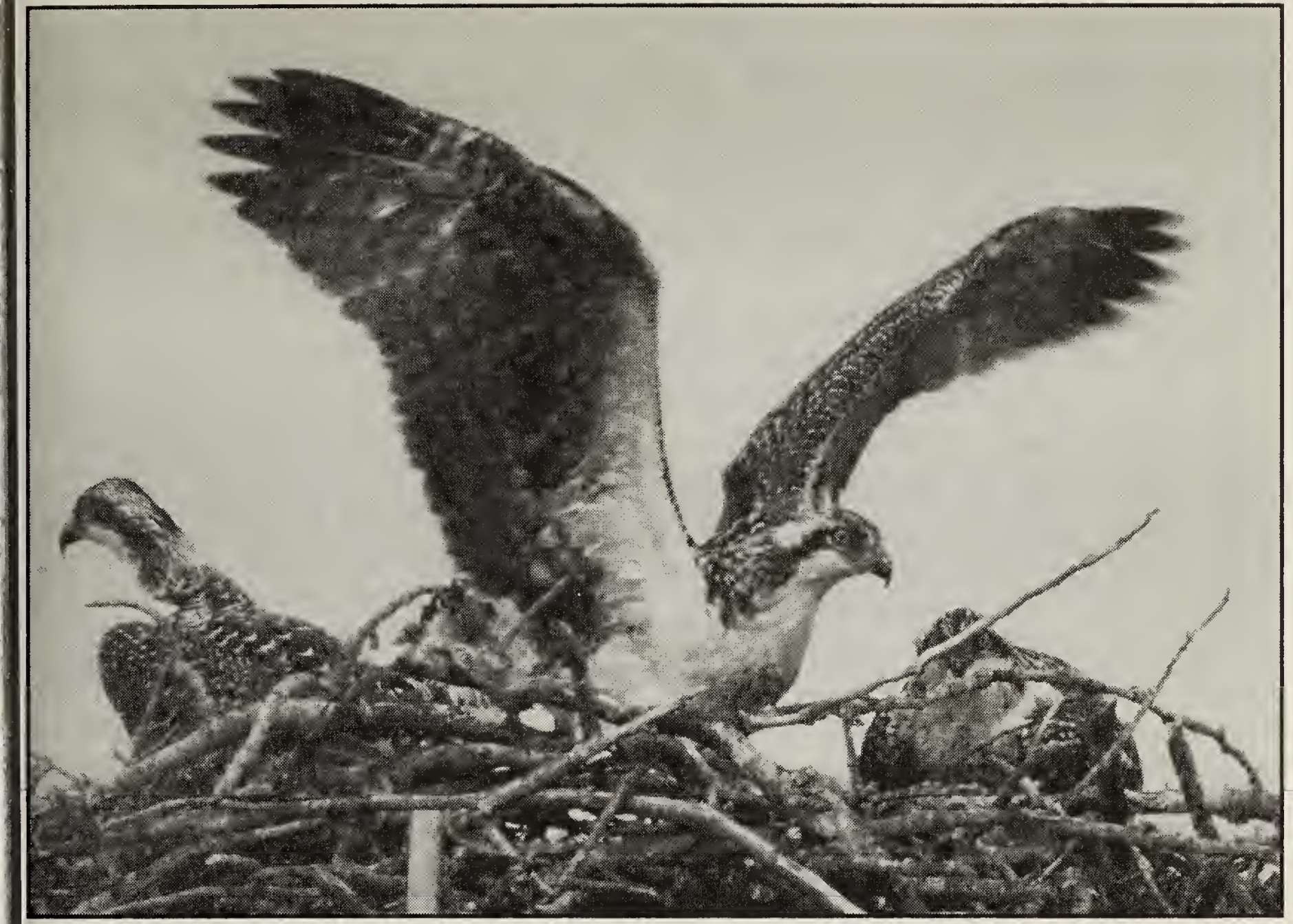

Figure 5. Adult male and 3 young.

Gerald Jones

seen at the nest site on September 21 .

Brown reports for the Osprey: "Contrary to the case in the majority of birds of prey, the nest still continues as a strong family link even when the young have become free-flying." He notes further that with both parents hunting, from three to five fish may be brought to the nest daily. "When one comes in with a fish it is taken to the eyrie and then one or more of the young will come gliding in from a perch nearby to share in the meal. Also for some days after first leaving the nest it may be used by all the young as a roost."2

With the installation of five additional poles by Manitoba Hydro, a second pair of Ospreys also nested in this area in 1997. This second nest, which I was able to observe on June 1 and 2, was in a wetlands area in Grand Beach Provincial Park. The nest pole in this nstance was $30 \mathrm{ft}$. high, with a $35 \mathrm{ft}$. perching pole about $200 \mathrm{ft}$. away. I saw the female on the nest and the male on the perching pole tearing at a fish. I was informed that one young was being fed on June 28 , while the male again sat on the perching pole. Many Red-winged Blackbirds were reported pestering the female Osprey on July 1 ; a member of the Manitoba Hydro crew indicated that this had been observed ever since the female had begun to sit on the nest. The male Osprey apparently went to the nest four times with a fish, but was pestered so much by the blackbirds that he had to leave for the perching pole. I was told that two young could be seen flapping their wings and that they were now feeding themselves with fish brought to the nest by the parents. On August 25 it was noted that the two young had left the nest.

Available breeding records of the Osprey in Saskatchewan, 1914-1976, were listed in the Blue Jay. ${ }^{6}$ The effect 
of man-made platforms on Osprey reproduction in one area of Saskatchewan has also been described. ${ }^{5} \mathrm{~A}$ special bulletin detailing construction of Osprey nest platforms has been published. ${ }^{3}$ The author of that report, P.J. Ewins, notes:

"Ospreys...have been increasing rapidly in many parts of North America since the mid-1970s, when organochlorine pesticides were withdrawn from widespread use. In the Great Lakes region and elsewhere these increases have been facilitated greatly by people installing artificial nest structures, particularly in areas where preferred natural nest sites are now scarce...." It is gratifying to know that due to man's caring intervention this magnificent bird is making such a successful comeback.

\section{Acknowledgements}

I wish to thank the crew of Manitoba Hydro and staff of Natural Resources at Grand Beach, especially Rod Cotton, for their efforts and their information. Gerald Jones, who has been observing the Grand Marais Ospreys closely for many years, and Letty and Ernie Taylor of Grand Marais, deserve thanks for providing information and photos. My deep appreciation is expressed to Robert Nero for his critical review of this paper. Gordon G. Graham kindly assisted with typing and entered the MS on a word processor.

\section{Literature Cited}

1.BANCROFT, J. 1992. Observations of the Osprey. Blue Jay 50: 31-32.

2.BROWN, P. 1964. Birds of prey. Andre Deutsch Ltd., London, UK. 124pp.

3.EWINS, P.J. 1994. Artificial nest structures for Osprey. Can. Wildl. Serv., Environment Canada, Ottawa. 41pp.

4.GODFREY, W.E. 1986. Birds of Canada. Natl. Mus. Nat. Sci. Ottawa. 595pp.

5.HOUSTON, C.S., \& F. SCOTT. 1992. The effect of man-made platforms on Osprey reproduction at Loon Lake, Saskatchewan. J. Raptor Research 26: 152-158.

6.HOUSTON, C.S. et al. 1977. Osprey nesting records in Saskatchewan. Blue Jay 35: 38-41.

7.LISTON, T.M. 1996. Bald Eagle attacks Osprey nestlings. Loon 68: 238-239.

8.VANDERBURGH, D.C. 1993. Manitoba Hydro accommodates Osprey activity. Blue Jay 51: 173-176.

9.VANDERBURGH, D.C. 1997. Midcontinent platform nesters. Blue Jay 55: 152-154.

Rock Doves were domesticated in the Mediterranean area around $5-10,000$ years ago.

A good homing Rock Dove can fly $800-1000 \mathrm{~km}$ per day. 